\title{
¿Aneurisma verdadero o pseudoaneurisma ventricular izquierdo?
}

\section{True aneurism or left ventricular pseudoaneurism?}

\author{
Alejandro Villanueva Afán de Ribera*, María Luisa Salto Camacho \\ y Francisco Herrera Ciudad
}

Servicio de Cardiología, Hospital Rey Juan Carlos, Móstoles, Madrid, España

Disponible en Internet el 15 de noviembre de 2017

\section{PALABRAS CLAVE}

Aneurisma ventricular;

Pseudoaneurisma ventricular;

Resonancia magnética cardiaca;

Trombo ventricular

\section{KEYWORDS}

Ventricular aneurysm;

Ventricular pseudoaneurysm;

Cardiac magnetic resonance image;

Ventricular trombus

Varón de 51 años, ingresado en junio de 2012 por primer episodio de insuficiencia cardiaca y derrame pericárdico severo, sin clínica de angor. El ecocardiograma (ETT) demostró disfunción ventricular izquierda severa. Se realizó

\footnotetext{
* Autor para correspondencia.

Correo electrónico: alxvillanueva@gmail.com
}

(A. Villanueva Afán de Ribera). cardiorresonancia (RM) que confirmó la disfunción ventricular izquierda severa (FEVI 22\%) por un aneurisma ventricular septo-apical con captación transmural en secuencias de realce tardío; también se identificó trombo en el interior del aneurisma (fig. 1, flechas blancas). Un ETT de 2016, con el paciente anticoagulado, identificó en la región septo-apical una imagen hipoecoica en forma de media luna, entre el pericardio visceral y la pared miocárdica, sin trombo en su interior (fig. 2 C, flecha blanca), compatible con pseudoanerisma ventricular. Tras la administración de contraste, no se visualizó paso del mismo al interior de la cavidad (ver videos. Material adicional disponible en la web). Se suspendió la anticoagulación por el riesgo de rotura.

Se solicitó una tomografía axial computarizada cardiaca que describió una gran dilatación en la zona septo-apical ventricular izquierda, nuevamente ocupada por un gran trombo que no permitió distinguir una solución de continuidad (fig. 3).

Al revisar los ETT desde 2012 se apreció la evolución de la imagen desde un aneurisma verdadero ventricular izquierdo con trombo (fig. 2A) a un pseudoaneurisma (2C). Al ver esta evolución con ETT, se concluyó que en realidad se trataba de un pseudoaneurisma con trombo en su interior, que desaparecía de manera intermitente en función de la 


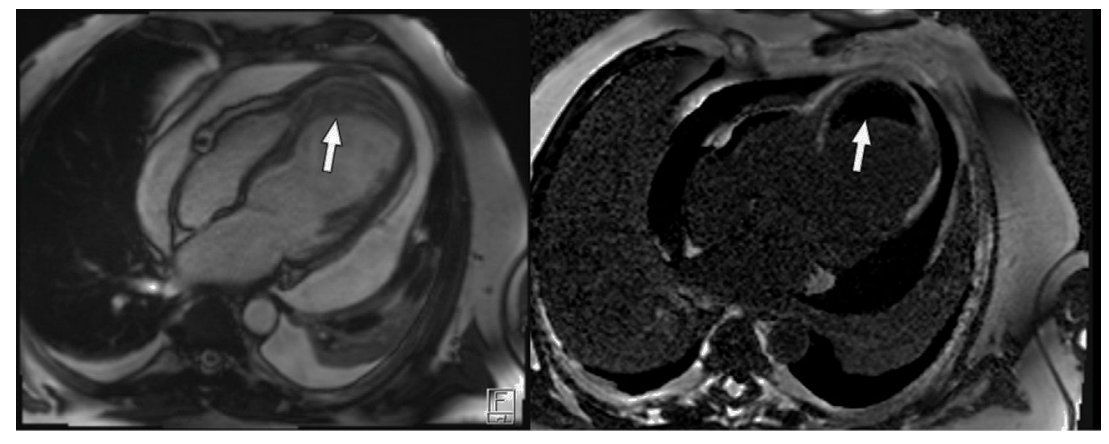

Figura 1

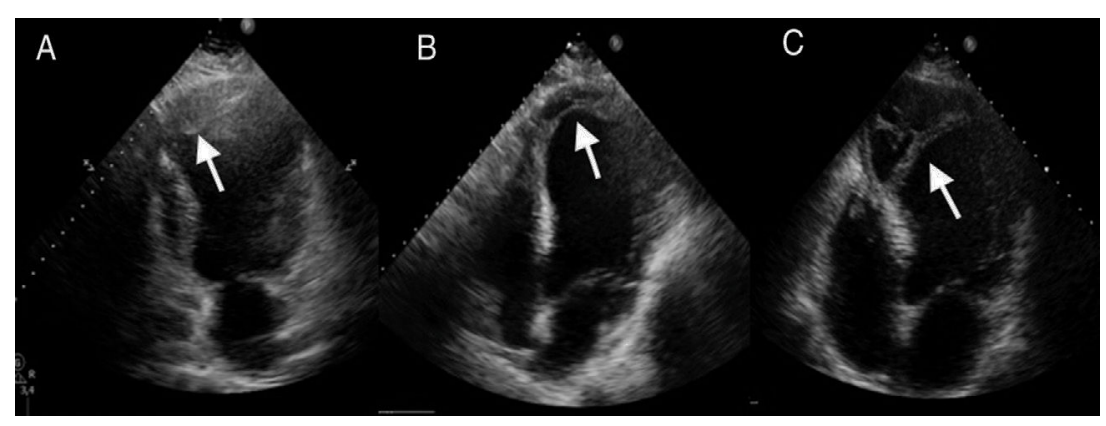

Figura 2

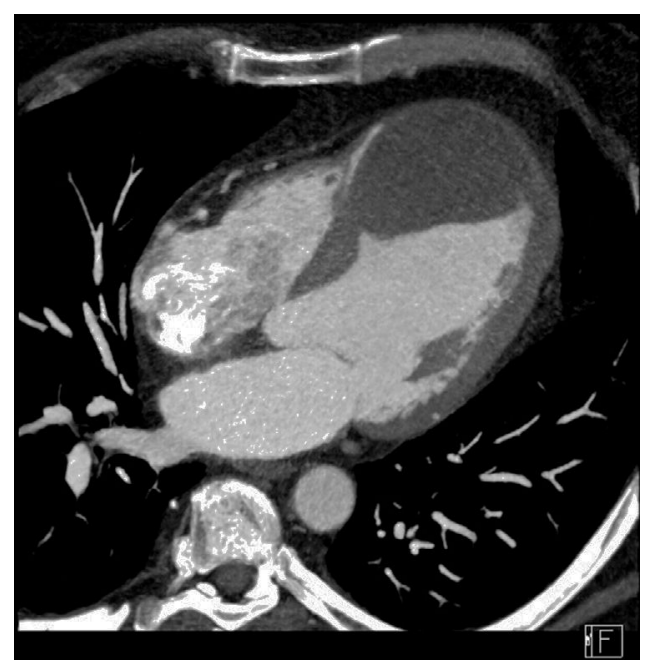

Figura 3 anticoagulación, lo cual dificultaba la visualización con RM/TAC. Este caso ejemplifica cómo una aproximación con diferentes técnicas de imagen puede ser clave para diagnosticar un pseudoaneurisma.

\section{Anexo. Material adicional}

Se puede consultar material adicional a este artículo en su versión electrónica disponible en doi:10.1016/j.rccar. 2017.06.009 